\title{
R438H Missense Mutation Related Generalized Resistance to Thyroid Hormone (GRTH): A Case Series Report in Three Generations
}

\author{
Hadeel Bashir, Jawad Bashir, Ali Bin Waqar, Irfan Khan, Tamar Saeed, Khaliq Hamdan
}

\section{INTRODUCTION}

We present a case series of generalized resistance to thyroid hormones (GRTH) running in three successive generations of a family due to a point mutation. The index case was a 45 year old female presenting with features suggestive of thyrotoxicosis and was inappropriately diagnosed as Graves disease receiving carbimazole initially followed by radio-iodine ablation in 1995. TSH was not measure at initial presentation. Post radio-ablative thyroxine replacement was commenced at 8 weeks but the TSH remained inappropriately unsuppressed despite prescribing supraphysiological dosages of thyroxine (Table below).

\begin{tabular}{|l|l|l|l|}
\hline TFT post radio-iodine therapy \\
\hline Weeks & $\begin{array}{l}\text { FT4 (pmol/I) } \\
(11-26)\end{array}$ & $\begin{array}{l}\text { TSH (mU/L) } \\
(0.4-3.8)\end{array}$ & $\begin{array}{l}\text { Thyroxine } \\
\text { (mcg/day) }\end{array}$ \\
\hline 8 & 8 & $>100$ & 50 \\
\hline 16 & 10 & $>100$ & 100 \\
\hline 24 & 19 & $>100$ & 150 \\
\hline 40 & 28 & 66 & 200 \\
\hline 46 & 33 & 12 & 250 \\
\hline 52 & 32 & 7 & 300 \\
\hline 60 & 52 & 1.6 & 300 \\
\hline
\end{tabular}

secreting pituitary adenoma or GRTH. Initial pituitary imaging revealed gland enlargement on $\mathrm{CT}$ scan suggesting an underlying TSH secreting adenoma. Remaining pituitary hormonal profile (prolactin, IGF-1, cortisol, gonadotrophins) was normal.

Further investigations however revealed a normal $\alpha$ subunit with preserved TSH response to TRH stimulation suggesting the diagnosis of GRTH. This was confirmed on genetic analysis to be secondary to a missense point mutation substituting arginine to histidine at amino acid $438(\mathrm{R} 438 \mathrm{H})$ in thyroid hormone receptor beta (TR- $\beta$ ).

The initial impression was co-existence of GRTH and thyrotropinoma or development of autonomous pituitary tumor with GRTH. However, supra-physiological doses of thyroxine led to complete resolution of pituitary enlargement after 22 months suggesting a reversible pituitary enlargement in the background of GRTH. No pituitary surgery was considered due to sparing of optic chiasm and the preserved visual fields.

\section{FAMILY SCREENING:}

The index case had a family history of thyroid disease including her grandmother, mother and aunt who had goitres requiring thyroidectomies but were deceased at the time of her presentation. Further family screening with thyroid function tests detected transmission of GRTH in three successive generations.

Case: 2 Daughter of index case also had inappropriately high TSH with high FT4 levels. She didn't require treatment. She was informed of the possibility of transmission of the same mutation to her children and the possibility of temporary hypothyroidism in new born if she became pregnant.

Case: 3 A 2 year old child (grand-daughter of the index case) was also shown to have inappropriately raised TSH and FT4. The child is under follow up with the paediatric endocrinologist but has no evidence of stunted growth or mental retardation.

\section{FAMILY TREE \\ Z Index case

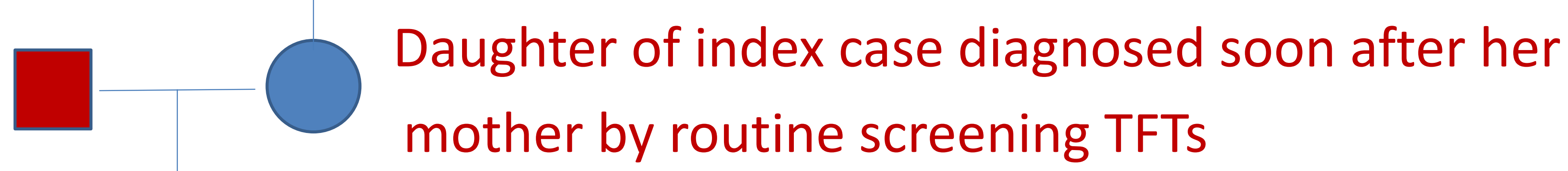

Grand daughter of index case diagnosed at age of 2 year

\begin{tabular}{|l|l|l|l|l|l|l|l|}
\hline Case Family history & DOB & Presenting feature & TSH & T4 & T3 & Diagnosed \\
\hline 1 & Index case (deceased) & $18 / 05 / 51$ & Thyrotoxicosis & 13 & 39.3 & 6.1 & $7 / 6 / 1995$ \\
\hline 2 & Daughter of index case & $5 / 10 / 77$ & Asymptomatic & 5.9 & 41.3 & 10.5 & $28 / 11 / 1997$ \\
\hline 3 & Grand daughter of index case & $11 / 1 / 12$ & Asymptomatic & 6.63 & 47.2 & & $22 / 05 / 2014$
\end{tabular}

\section{DISCUSSION}

This case series in a family highlights the importance of appropriately diagnosing rare conditions like thyroid hormone resistance in order to prevent administering inappropriate therapies. The index case was challenging despite not having an initial proper assessment by taking TSH into consideration (1). The presence of pituitary enlargement is not an unusual phenomenon with GRTH and pituitary hyperplasia has been reported in several animal studies as well as in human autopsy findings and case reports $(2,3)$. However, the co-existence of these two differentials together can often make a diagnostic dilemma leading to inappropriate therapeutic interventions $(4,5)$. While interpreting the unusual thyroid function tests, it is vital to take into consideration the clinical presentation and seek specialist input before commencing any therapeutic options (6,7). Most cases present with asymptomatic goitre but others may be having features of thyrotoxicosis (as in our index case). Detection of one index case by genetic testing leads to family screening via routine thyroid function tests to confirm or refute the diagnosis of GRTH. Although there have been case reports of autosomal recessive inheritance yet most cases are autosomal dominant (like in our cases series). Family screening avoids inappropriate therapeutic interventions especially in routine TFTs done at primary care level.

\section{References}

1. Gurnell M, Rajanayagam O, Barbar I, Jones MK, Chatterjee VK. Reversible pituitary enlargement in the syndrome of resistance to thyroid hormone. Thyroid. 1998 Aug;8(8):679-82.

2. Scheithauer BW, Kovacs K, Randall RV, Ryan N. Pituitary gland in hypothyroidism. Histologic and immunocytologic study. Arch Pathol Lab Med. 1985 Jun;109(6):499504.

3. Marazuela M, Nattero L, Moure D, Garcia-Polo I, Figueroa-Vega N, Guijarro C. Thyroid hormone resistance and pituitary enlargement after thyroid ablation in a woman on levothyroxine treatment. Thyroid. 2008 Oct;18(10):1119-23.

4. Safer JD, Colan SD, Fraser LM, Wondisford FE. A pituitary tumor in a patient with thyroid hormone resistance: a diagnostic dilemma. Thyroid. 2001 Mar;11(3):281-91.

5. Watanabe K, Kameya T, Yamauchi A, Yamamoto N, Kuwayama A, Takei I, et al. Thyrotropin-producing microadenoma associated with pituitary resistance to thyroid hormone. J Clin Endocrinol Metab. 1993 Apr;76(4):1025-30.

6. Gurnell M, Halsall DJ, Chatterjee VK. What should be done when thyroid function tests do not make sense? Clin Endocrinol (Oxf). 2011 Jun;74(6):673-8.

7. Koulouri O, Moran C, Halsall D, Chatterjee K, Gurnell M. Pitfalls in the measurement and interpretation of thyroid function tests. Best Pract Res Clin Endocrinol Metab. 2013 Dec;27(6):745-62. 